\title{
Study on Long-Term Generation Expansion Planning upon the LNG Price Fluctuations
}

\author{
Min-Chul Kim, Soon-Hyun Hwang, Seok-Man Han, Balho. H. Kim \\ Hong-Ik University, Seoul, South Korea., KEMCO \\ Email: alscjf03@hanmail.net, kerobes13@nate.com, bhkim0711@gmail.com
}

Received April, 2013

\begin{abstract}
About 37\% of South Korea's greenhouse gas emission is from electricity generation. Most of the country's electric power is fundamentally generated by nuclear, thermal and LNG facilities. And LNG, of them, is characterized to require high cost for power generation but $\mathrm{CO}_{2}$ coefficient is lower than thermal generation. Amid the ongoing global efforts to tackle global warming, shale gas introduction and changing global environment, LNG prices are expected to fluctuate. Against this backdrop, this paper seeks to perform scenario tests on LNG fuel cost fluctuation and examine its long-term effects on generation expansion planning.
\end{abstract}

Keywords: LNG, Shale Gas; Generation Expansion Planning; Price Fluctuation

\section{Introduction}

About $37 \%$ of South Korea's greenhouse gas emission is from electricity generation. Most of the country's electric power is fundamentally generated by nuclear, thermal and LNG facilities. And LNG, of them, is characterized to require high cost for power generation but $\mathrm{CO} 2$ coefficient is lower than thermal generation. Amid the ongoing global efforts to tackle global warming, shale gas introduction and changing global environment, LNG prices are expected to fluctuate. Against this backdrop, this paper seeks to perform scenario tests on LNG fuel cost fluctuation and examine its long-term effects on generation expansion planning.

\section{Factors for LNG Price Fluctuation}

\subsection{International LNG Supply/Demand \& Price Movement}

The world's natural gas production, as of 2010, is approximately 2.35 billion ton. And 1.64 billion ton or $69 \%$ of the production is consumed within countries of production themselves and the remaining 720 million ton is exported to other countries. As of 2011, 5 Asian countries - Japan, South Korea, India, Taiwan and China - are mainly importing the LNG, accounting for $63 \%$ of the global LNG importation. The US increased own LNG production, reducing import by $13 \%$ from the previous year to 60 billion ton in 2011 .

LNG trading, for its own nature, normally takes place based on long-term contracts. But with the recent rise in shale gas production, LNG supply surplus also climbed, causing some people who take profit from different prices between regions. In this situation, short-term based trading has risen.

Looking at regional price movement, we can notice that Atlantic market prices are weaker and Northeast Asian market prices are going up long with its high oil prices and spot prices. Figure 1 below shows price movement of natural gas and oil [1].

In Figure 1, Japan shows faster increase of spot prices than long-term contract prices after the Fukushima nuclear accident. South Korea maintains lower import price than Japan for its lower share of spots.

\subsubsection{Shale Gas Reserves \& Production Ratio}

The Shale gas reserves found so far is estimated at approximately 187.4 trillion $\mathrm{m}^{2}$, an amount to support the world for about 6 decades. If put in terms of thermal unit,

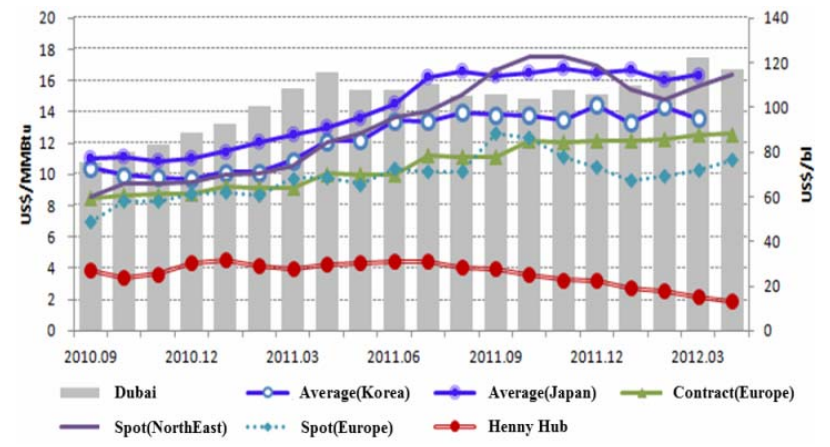

Figure 1. Natural Gas/Oil price movement. 
Table 1. Comparison of traditional gas reserves and shale gas reserves.

\begin{tabular}{lcccc}
\hline & \multicolumn{2}{c}{ Traditional Gas } & \multicolumn{2}{c}{ Shale Gas } \\
\cline { 2 - 5 } Country & $\begin{array}{c}\text { Reserve } \\
\left(\text { Trillion } \mathrm{m}^{3}\right)\end{array}$ & $\begin{array}{c}\text { Portion } \\
(\%)\end{array}$ & $\begin{array}{c}\text { Reserve } \\
\left(\text { Trillion }^{3}\right)\end{array}$ & $\begin{array}{c}\text { Portion } \\
(\%)\end{array}$ \\
\hline US/Canada & 9.4 & 5 & 35.4 & 19 \\
China & 2.8 & 2 & 36.1 & 19 \\
Europe & 18.3 & 10 & 17.7 & 9 \\
Russia & 44.8 & 24 & - & - \\
Middle East & 75.8 & 41 & - & - \\
Global & 187.1 & 100 & 187.4 & 100 \\
\hline
\end{tabular}

shale gas would be 168.7 billion toe and oil, 188.8 billion toe. This is pretty vast amount of reserves. For this result, 31 countries were surveyed so more countries could be included in the future. The world's potential reserve is estimated at 635 trillion $\mathrm{m}^{3}$, which could sustain for two more centuries.

As of 2011, shale gas production accounts for $28 \%$ of the total natural gas production and is expected to rise to $50 \%$ by $2035[2]$.

\subsection{Global LNG Market Outlook}

From a short-term perspective, LNG demand is likely to surge as more people show opposition to nuclear power generation and try to find its alternative. But in the longterm, LNG prices are projected to fall mainly because of diverse shale gas-based export projects in many countries including the US and Canada. From 2020, China, which holds the largest shale gas reserves, will start to produce in full scale and contribute to further price drop.

\section{Application of Generation Expansion Planning Model}

\subsection{Generation Expansion Planning}

Generation expansion plan refers to annual plans on power plant construction established in order to satisfy growing national demand for electricity with diverse units having different features such as construction cost, fuel cost and operational characteristics [3]. The purpose of designing the generation expansion plan is to secure the most economic source of power that could help maintain supply reliability for a given estimated electricity demand every year.
In pursuing this study, we plan to employ a computation model developed by the Economy in Electricity Research Center of Hong-ik University to come up with optimal yearly generation expansion plans reflecting RPS (Renewable Portfolio Standard) for power companies.

\subsection{Computation Model Algorithm}

The computation model obtains the optimal plan based on Dynamic Programming method [4]. The composition of the computation model is similar to WASP model, which is used for South Korea's generation expansion planning but for the fact that the former has only 4 basic modules unlike the latter which has 6. Each module is operated individually and their results are made in a file as an input to other modules. In this way, the model functions consistently, realizing easy and fast process to get results.

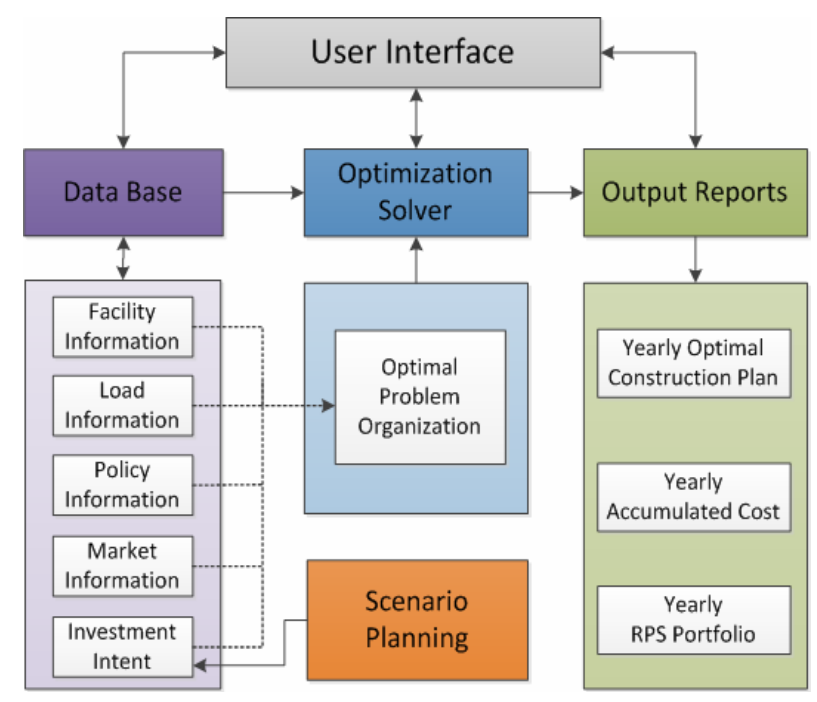

Figure 2. Computation model outline.

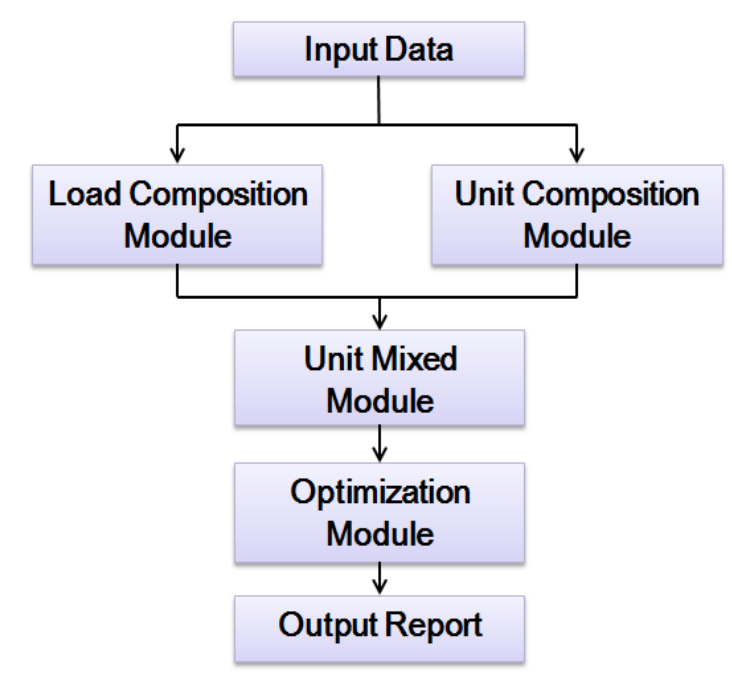

Figure 3. Computation model composition. 


\subsection{Mathematical Formalization}

The issue of optimal power resource composition with cost-efficiency can be formalized as follows:

$$
\begin{aligned}
& M I N \sum_{t=1}^{T}\left(\sum_{i=1}^{I} G_{t}\left(X P_{t}^{1}, \cdots, X P_{t}^{I}\right)+J_{t}\left(u_{t}^{1}, \cdots, u_{t}^{I}\right)\right) \\
& \text { s.t. } X P_{t}^{i} \leq x_{t}^{i} \\
& \quad \sum_{i}^{I} L O L P_{t}\left(x_{t}^{1}, \cdots, x_{t}^{I}\right) \leq C_{t} \\
& \quad \sum_{i}^{I} C O_{2}\left(X P_{t}^{1}, \cdots, X P_{t}^{I}\right) \leq C a p_{t} \\
& x_{t}^{i}=x_{t-1}^{i}+u_{t}^{i} \\
& u_{t}^{i, \min } \leq u_{t}^{i} \leq u_{t}^{i, \max }
\end{aligned}
$$

where,

$$
\begin{aligned}
& \text { t : Year } \\
& \mathrm{T} \quad \text { : Period of the plan } \\
& \text { i : : Type of the plant } \\
& \text { I : Total number of plant types } \\
& x_{\frac{1}{2}} \quad \text { : Capacity of unit ' } \mathrm{i} \text { ' in year ' } \mathrm{t} \text { '(MW) } \\
& \mathbf{u}_{t}^{\mathrm{i}} \quad \text { : Capacity of unit type 'i’ which will be in- } \\
& \text { serted in year ' } \mathrm{t} \text { ' } \\
& \text { : Total generation amount of plant type 'i’ in } \\
& \text { year ' } \mathrm{K} \text { ' } \\
& \mathrm{G}_{\mathrm{\textrm {z }}} \quad \text { : Total operation cost in year ' } \mathrm{t} \text { '(KRW) } \\
& \text { It : Total construction cost in year ' } \mathrm{t} \text { '(KRW) } \\
& \text { LOLR: : Supply reliability in year ' } \mathrm{t} \text { '(LOLP) } \\
& \mathbf{C}_{\mathrm{t}} \quad \text { : Criterion of supply reliability in year ' } \mathrm{t} \text { ' } \\
& \mathrm{CO}_{2}\left(\mathrm{x}_{t}^{1}\right) \text { : Amount of } \mathrm{CO}_{2} \text { emissions w } \\
& \begin{array}{l}
\text { Capt : Total permissible mount of the Emission in } \\
\text { year ' } t \text { '(ton) }
\end{array} \\
& \mathrm{u}_{\mathrm{f}}^{\mathrm{jm} \min } \quad \text { : The minimum construction capacity in year } \\
& u_{\mathrm{i}}^{\mathrm{fm} \max } \text { : The maximum construction capacity in year }
\end{aligned}
$$

Equation (1) represents a cost-minimization function and consists of annual operational cost and construction cost. Equation (3) is a constraint to check if the given facility can uphold the reliability while meeting the demand at ' $t$ ' year. Any unit combination that does not meet this constraint is excluded from a state. Equation (6) put both upper and lower limits on the number of possible new units to be built each year to prevent concentration in building only specific power source facilities while ensuring the practicality of its resulting values. The value of $u_{t}^{i}$ that satisfies such conditions and minimizes the function at the same time is the very plan of potential yearly power facility construction and it is the generation expansion plan with minimum cost.

\section{Case Study}

\subsection{Scenario Designing}

In this paper, based on the 5th National Long-term Electricity Plan's input data, we analyzed scenarios to draw reasonable options of power source combination according to LNG price fluctuation. We plotted a scenario exclusively based on the 5th National Long-term Electricity Plan for every condition and the years covered herein were from 2013 to 2027. Discount rate was set at $6.5 \%$. RPS was employed for new and renewable energy policy. As for supply reliability, LOLP (0.5 days/year) was used and reserve rate was set at 20 30\%. To carry out the supply plan scenarios according to LNG price fluctuation as sought by this study, we set LNG fuel cost at 67.145 (1000 KRW/Gcal).

\subsection{Scenario Results}

The total accumulated cost changes depending upon LNG price decreased by $6.6 \%$ and $15.06 \%$ when $30 \%$ and $50 \%$, respectively. However, the yearly unit mix exhibited no change in the final year's unit composition. This is maybe because, the total cost drop was only due to the reduced fuel cost for LNG units and no change in construction cost. Even if LNG prices fall by 50\%, they still may not have any competitive edge over other power sources.

\section{Conclusions}

This study examined changes in generation expansion plans according to natural gas price fluctuation, based on the data of the 5th National Long-term Electricity Plan of South Korea. LNG is a basis power source accounting for $22 \%$ of the country's total power generation but it is true that its economic feasibility is poorer than that of nuclear power generation and thermal generation. With the planned introduction of shale gas, however, LNG demand is expected to change along with global situation. And these will further change fuel costs. It is viewed possible that in such a situation, LNG could improve its economic feasibility to compete with other sources. LNG,

Table 2. LNG Price Fluctuation Scenario.

\begin{tabular}{cc}
\hline No. & Scenario \\
\hline 1 & base LNG Fuel Cost \\
2 & Fuel Cost reduced $30 \%$ beside base scenario \\
3 & Fuel Cost reduced 50\% beside base scenario \\
\hline
\end{tabular}


Table 3. Comparision of Accumulated Cost According to LNG Price Fluctuation (unit : 1000 KRW).

\begin{tabular}{|c|c|c|c|}
\hline \multirow{2}{*}{ Year } & \multicolumn{3}{|c|}{ Accumulated Cost } \\
\hline & Scenario 1 & Scenario 2 & Scenario 3 \\
\hline 2013 & 39,912,925 & $56,018,261$ & $52,918,520$ \\
\hline 2014 & $81,574,861$ & $87,227,204$ & $83,095,508$ \\
\hline 2015 & $116,988,931$ & $114,948,710$ & $109,093,258$ \\
\hline 2016 & $153,351,641$ & $143,736,800$ & $135,600,278$ \\
\hline 2017 & $187,306,499$ & $173,417,151$ & $162,430,957$ \\
\hline 2018 & $224,352,211$ & $203,639,970$ & $191,461,086$ \\
\hline 2019 & $251,493,238$ & 231,893,647 & $214,517,156$ \\
\hline 2020 & $277,168,901$ & $257,317,087$ & $237,166,953$ \\
\hline 2021 & $300,865,281$ & $280,083,160$ & $257,412,066$ \\
\hline 2022 & $322,747,702$ & $301,269,670$ & $276,362,852$ \\
\hline 2023 & $340,714,484$ & $318,530,822$ & $291,490,594$ \\
\hline 2024 & $356,234,529$ & $334,221,630$ & $305,406,923$ \\
\hline 2025 & $371,344,908$ & $347,869,028$ & $317,341,374$ \\
\hline 2026 & $385,518,003$ & $360,600,010$ & $328,416,224$ \\
\hline 2027 & $399,100,524$ & $372,761,470$ & $338,976,995$ \\
\hline
\end{tabular}

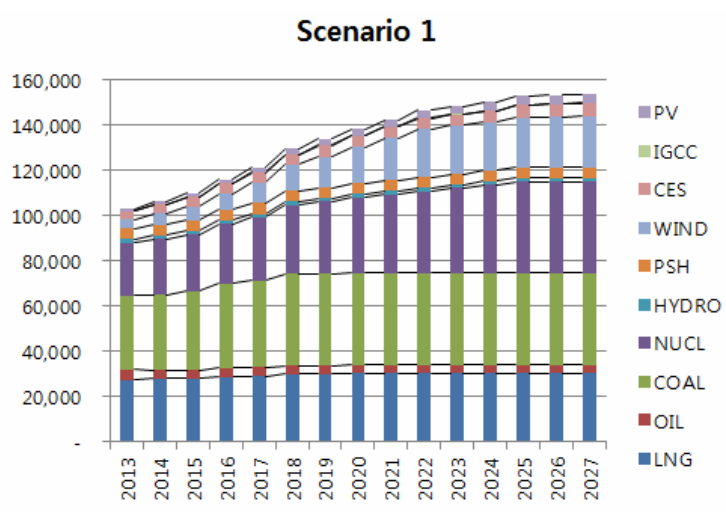

Figure 4. Accumulated cost movement of scenario 1.

Scenario 2

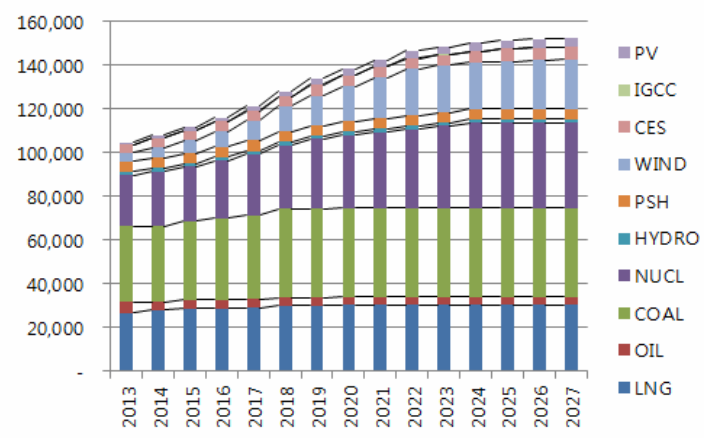

Figure 5. Accumulated Cost Movement of Scenario 2.

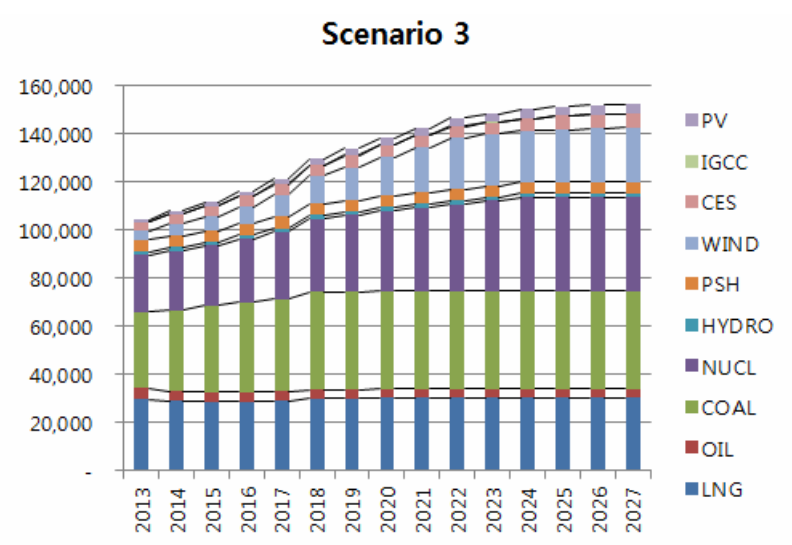

Figure 6. Accumulated Cost Movement of Scenario 3.

Table 4. Accumulated cost movement against base scenario.

\begin{tabular}{cccc}
\hline & $\begin{array}{c}\text { Accumulated } \\
\text { cost } \\
\text { (KRW 1000) }\end{array}$ & $\begin{array}{c}\text { Against } \\
\text { base scenario }\end{array}$ & $\begin{array}{c}\text { Against base } \\
\text { scenario (\%) }\end{array}$ \\
\hline Scenario 1 & $399,100,523,729$ & - & - \\
Scenario 2 & $372,761,470,217$ & $-26,339,053,512$ & $-6,60 \%$ \\
Scenario 3 & $338,976,995,496$ & $-60,123,528,233$ & $-15.06 \%$ \\
\hline
\end{tabular}

with its low greenhouse emission, could become a reliable basis source of generation and contribute to supplying electricity at a lower cost if supported by better technologies to reduce construction cost.

For future studies, we believe more sophisticated outcomes could be obtained if the fuel cost, which was set at a single amount throughout the whole involved period in this study, is separated for each year. Other environmental policies including ETS (Emission Trading System) - another plan to reduce greenhouse gas emission - may also be employed in further studies.

\section{Acknowledgements}

This research has been supported by Hong-ik University Industry-Academia Cooperation Foundation funded by WP (Korea Westernpower co., Ltd)

\section{REFERENCES}

[1] Korea Energy Economics Institute, "International LNG price trends and future prospects and implications," 2012

[2] K. J. Kim, "Shale Gas Developments and ramifications," The 29th Energy forum, The National Academy of Engineering of Korea, 2012.

[3] Y. C. Kim, "Multi-Criteria Generation Expansion Planning with Global Environmental Considerations,” Korea advanced institute of science and technology, 1993.

[4] Y. C. Kim, "Principle of the Generation Expansion Plan- 
ning,” Korea Energy Economics Institute M\&B, 2006.

[5] E. R. Peterson, "A dynamic Programming model for the expansion of electric power systems," Management Science, Vol. 20, No. 4, 1973, pp. 656-644.

doi:10.1287/mnsc.20.4.656

[6] J. W. Ann, "A Study on Power Expansion Planning Model Considering the Emission Trading," The Transac- tions of the Korean Institute of Electrical Engineers, Vol. 61, No. 7, 2012, pp. 957-965. doi:10.5370/KIEE.2012.61.7.957

[7] KPX, "The 5th Korea national Long-term Electricity Plan”.

[8] EPSIS Homepage, http://www.kpx.or.kr/epsis/. 